\title{
Metacommunication as Second Order Communication
}

\author{
KOME - An International Journal of Pure \\ Communication Inquiry \\ Volume 5 Issue 1, p. 80-90. \\ (C) The Author(s) 2017 \\ Reprints and Permission: \\ kome@komejournal.com \\ Published by the Hungarian Communication \\ Studies Association \\ DOI: 10.17646/KOME.2017.15
}

\section{Samuel Mateus \\ Madeira University, Portugal}

\begin{abstract}
By giving full emphasis to the impossibility of not to communicate, the first axiom of communication stresses how communication is an event not subject to cessation. It is this never-ending characteristic that impels us to the need to ponder on metacommunication as "communication about communication". By taking a philosophically informed and pragmatic stance, this paper deals with the concept of "metacommunication" and tries to incorporate it in the theory of communication. It posits communication is a multilevel dialectical happening in which metacommunication presents itself a kind of second order communication. The paper describes communication as an ad infinitum process in which every communication supposes always more communication. Metacommunication is the answer to the relationship level of communication and that's why we postulate metacommunication as a re-communicating communication.
\end{abstract}

Keywords: Metacommunication; Communication Theory; Pragmatics of Human Communication; Bateson; Watzlawick; Metaporo

"Language commonly stresses only one side of any interaction" Gregory Bateson, (1979) Mind and Nature: A Necessary Unity. New York: E. P. Dutton, p.56

\section{Introduction}

One of the everlasting questions that Communication Theory answers is: what is "communication"? Despite the theoretical differences and scientific ambitions between them, several authors, from Dewey (1927) to Shannon \& Weaver (1949) or Watzlawick et ali. (1967) point to its "processus" aspect. Yet, considering communication as a symbolic process does not immediately give us a complete answer regarding its nature. Is communication a kind of vehicle giving place to a process of information transportation, a transitional medium

Address for Correspondence: Samuel Mateus, email: samuelmateus[at]uma.pt

Article received on the 29th October, 2016. Article accepted on the 29th May, 2017.

Conflict of Interest: The author declares no conflict of interests. 
of meaning? Does the notion of "communication" contain clearly transmissible content? Can it be envisaged as sheer content and form?

In a speech entitled "Signature, Event, Context", Derrida asked: "Is it certain that to the word communication corresponds a concept that is unique, univocal, rigorously controllable, and transmittable: in a word, communicable? In accordance with a strange figure of discourse, one must, first of all, ask oneself whether or not the word "communication" communicates a determinate content, an identifiable meaning, or a describable value" (Derrida, 1988: 1).

Derrida is, of course, playing with common assumptions in order to deconstruct the concept itself and by doing so, it seems he is alluding to the common notion that to communicate is to "get someone to understand your thoughts or feelings or to give information about (something) to someone" (Merriam-Webster Dictionary Online). He is primarily trying to push the boundaries of what one can comprehend by communication ${ }^{1}$. Of course, there is a representational, directive, clearly transmissible content. It is communication's referential duty: to portrait something about the world. Derrida is also interested in theorizing the displacement of writing by reflecting upon the impossibility to fully saturate the context.

The reading of Derrida's oeuvre suggests a critical aspect to communication: the endless allocation of meaning, as if meaning entered a perpetual cycle. In other words, he posits an enlarged and general idea of communication. It is as if communication were a symbolic process that is always escaping us, always in self-reconfiguration. A process with no commencement and no dissolution (cf. Dance, 1967), in constant happening. More importantly, we can read Derrida's insights as a total possibility of meaning: one meaning does not impose itself to another.

This assumption on the total deference of meaning, it seems to us, is of vital importance to communication studies since we cannot ponder only the referential duty of communication. One should also consider its relationship aspect (Watzlawick et ali., 1967: 50). This means communicators entail a dynamic process where, along with representation, we need to consider expression (Porcar \& Hainic, 2011).

Communication is not a bridge between two separate atoms (cf. communication models based on the machine or billiard-ball (Sfez, 1992)) but a spiral and inclusive process where participants link to each other. Additionally, it is an expression of a relation between individuals; it is circular, interactive participation.

Since human communication happens between two subjectivities, the concept is constructed between the lines of the relations individuals are building while they socially interact. Beyond the communication messages, we encounter instructions that enable us to cope with one another. In other words, communication always presupposes a metacommunicative element or meta-message indicating how to be interpreted.

Seeing that it indicates how communication should be understood, communication always presupposes more communication. We must then think about the role of metacommunication - is it a mere substitute? Is metacommunication a kind of appendix to communication? Is it possible (and justifiable) to differentiate between a first and original communication and a second, metacommunicative communication? And how does the relation between them function?

Metacommunication is a fundamental feature of interaction and a key concept in communication (Andersen, 2009: 654). As the term was introduced in 1951,

\footnotetext{
${ }^{1}$ A more thoroughly analysis on Derrida's concept of communication can be found in the paper: "There is no outside of communication-Metacommunication at the light of Derrida's graphematic structure of communication" (Mateus, 2015).
} 
"metacommunication" has been adopted by different authors in the domain of psychiatry, education, business and communication. Esser, Reineman and Fan (2001), for instance, have applied the notion of metacommunication to the study of news coverage and spin doctoring arguing that "metacommunication (1) describes a new, third stage in election coverage after issue and strategy coverage; (2) reflects the mass media's new role as a political institution in the third age of political communication and (3) can be seen as the news media's response to a new, third force in news making and professional political PR".

Baltzersen (2013: 128), on the other hand, discusses "what specific types of metacommunication might facilitate good supervision in higher education. It is suggested that one should distinguish between metacommunication as part of a transparent communication style and metacommunication about the collaboration period in supervision". Nakano (2001) examines the Basic Structure of Metacommunication in Intersubjective Fun-Interactions between mothers and infants.

The concept was also used on organizational communication (Castor, 2017) and in interpersonal communications studies to codify and analyze interaction between individuals at the relational level (Rogers \& Escudero, 2004). In political studies, (Simons, 1994) metacommunication is a rhetorical tactic used in political debates e.g. politicians striving to cope with provocative questions by challenging the journalist's legitimacy for asking them. In the international relations and political science domains (Rich \& Craig, 2012), metacommunication is used as a key concept in Digital Media studies. Jensen (2016: 7), for instance, emphasizes, "the importance of meta-communication for contemporary communication theory, examines mediated presence as an instance of metacommunication, and addresses the implications of digitally mediated presence for current issues of surveillance".

The objective of this paper is to theoretically interrogate this imbrication between communication and metacommunication by taking, in contrast, a philosophically informed and pragmatic exploration of these concepts.

Metacommunication is communication beneath the surface. We will envision communication as a multilevel event in which metacommunication presents itself a kind of second order communication. We will describe what the expression may mean, taking communication as an ad infinitum process in which the communication always presupposes more communication.

Inspired by the philosophy of Derrida (1988), Serres (1969) and the idea of Metaporo (Marcondes Filho, 2012) we draw a theoretical perspective on communication as an unfolding notion that needs to be considered dynamically in its articulations with metacommunication.

We will, then, characterize the idea of metacommunication, establish it as a kind of second order communication and finally ponder on the consequences of this framework suggesting a notion of communication ad infinitum.

\section{Metacommunication: communication about communication}

Metacommunication is an additional communication, a never-ending "processus" that pushes communication away from simple codification of contents. Ultimately, it confirms the first axiom: one cannot not communicate (Watzlawick et al., 1967). This maxim is based on the assumption that behaviour has no opposite, in other words, one cannot cease to behave.

Since there is no counter-part to behaviour (an anti-behaviour) it is impossible not to communicate. Every behaviour is, thus, a form of communication. Besides, each behaviour 
has the value of a message. Activity or inactivity, each behaviour influences other behaviours.

The first axiom can be postulated as a metacommunicational principle of the pragmatics of communication (Watzlawick et al., 1967: 32). In simple terms, metacommunication may be understood as the possibility to indicate how information should be interpreted and may be congruent, to support or to contradict communication.

Since it is implicit and not expressed in words, it is a risky activity. Metacommunication is a complex concept, sometimes what one means is not what others interpret. Every time there is communication, there is also metacommunication linked to it making sense of the meaning.

Communication, in this regard, is a highly pragmatical activity. If I say "Do you want to come to the movies tonight?" and someone answers "I am studying this evening" with a shrug- in a proper context - we can infer according to the Principle of Cooperative Conversation (Grice, 1975) "thank you for the invitation but I am not really interested". At the same time, this conversational implicature resumes a meta-communication given that vocal intonation and face expression that accompanied the utterance and had taken the interlocutor to conclude that assertion meant a negative answer to the invitation.

We can now see that body language, for example, is an important part of metacommunication but metacommunicative competence, seen as the ability to identify, intervene and repair communication disruptions - involves also verbal communication (written or oral words), para-verbal communication (intonation, volume, interruptions, rhythm) and nonverbal communication (Birdwhistell, 1959) - Kinesics and Proxemics including gestures and facial expressions. Indeed, all symbolic systems can function as metacommunicative operators.

In some cases, the words metacommunicate body language enabling the subjects to interpret it in a context of a joke, for instance. Metacommunication supposes, then, that the subjects understands each other's code by repairing in the metacommunicative cues that send whenever they interact. It is these cues that enhance or disallow what we say with words. Metacommunication is also communication about what we mean by our communication.

What is really problematic is the meaning of "about" when we describe metacommunication as "communication about communication". When Ruesch \& Bateson's (1951: 209) define metacommunication, they do not deal extensively with what we should understand by "communication about communication". They simply described metacommunication as a "new order" of communication that arose in the evolution of mammals (Craig, 2016: 1). This other order of communication enabled them to explain some creative, complex and paradoxical attributes of social interaction. Ruesch \& Bateson (1951) tells us metacommunication is an act of communication, between two or more persons, that communicates something about either the communication itself, either the relationship between them, or both. It contains a potential to paradox since the adaptive and creative qualities of human communication destabilizes meanings and relational frames ${ }^{2}$. Since a message is always tied to a particular context, it implies a relationship dimension, thus, every message contains an implicit metacommunication about the relationship between the communicators that classifies or frames the message. Metacommunication is communication (relation) about communication (message).

Note that we are not using the word "metacommunication" in a commonly or clinical sense when it describes the explicit discussion in therapy groups about their here and now

\footnotetext{
${ }^{2}$ Robert Craig very pertinently relates Goffman's Frame Analysis to metacommunication. "Although Goffman does not discuss metacommunication explicitly, he distinguishes several forms of communication that function metacommunicatively, such as directional signals and ways of breaking frame" (Craig, 2016: 4).
} 
experience of social interaction. Nor are we limiting the term to the non-verbal signals that modify the meaning of verbal expressions, for example, in order to convey sarcasm. Although they are clearly consistent with Bateson's concept, these uses tend to simplify a complex process. Instead, we refer to metacommunication in a theoretical perspective attempting to query its depth as a key concept on Communication Theory.

We want now to go deeper into the concept of metacommunication and for this reason we will turn to the idea of interaction. We will address this question suggesting that interaction could lead the way to approach metacommunication as a second order communication.

This theoretical framing of metacommunication entails a redefinition of the communication notion and that is what will occupy us in the third section of this paper.

\section{Metacommunication as Second Order Communication}

In physics, interaction points to the direct effect that one kind of particle has on another. In communication studies, interaction may be broadly described as the study of the effects of communication between two or more agents. But as long as it concerns "a sequence of messages exchanged in a reciprocal relation" (Marc \& Picard apud Centeno, 2009: 36), the analysis of interaction culminates in the study of the autocorrections processes. In order for two individuals to successfully interact, they have to predict each other's behaviours as well as to modify their own actions when those predictions turn up wrong. The ability to autocorrect ones own actions is based on the capacity of the individual to predict events in the reciprocal relationship (Centeno, 2009: 36).

At an interpersonal level, we observe these autocorrection processes by the presence of three elements: expressive acts; conscious or unconscious perceptions of those expressive action made by other persons; and re-sent information that those expressive actions were perceived (and implicitly acknowledged) by others (Ruesch \& Bateson, 1951: 208).

Metaperception is thus a crucial point. It is the perception to be perceived that significantly changes human communication. "If I know that the other person perceives me and he knows that I perceive him, this mutual awareness becomes a part determinant of all our action and interaction" (Ruesch \& Bateson, 1951: 208).

Metaperception, or the perception of perception, signs an implicit agreement and supposes the recognition of mutual influence. By entering and recognizing the field of mutual awareness, one steps into a communication system in which the other determines his action by integrating (accepting and responding to) my behaviours. In effect, it is the perceived perceptions that constitute a communicative field between two persons.

Ruesch \& Bateson (1951: 209) specify some criteria for mutual awareness: "(a) signals whose only meaning would be the acknowledgment of a signal emitted by another; (b) signals asking for a signal to be repeated; (c) signals indicating failure to receive a signal; (d) signals which punctuate the stream of signals; and so on. With complete awareness of the other's perception an individual should stop repeating a signal after it has been received and acknowledged by the other individual, and this type of self-correction would indicate mutual".

Ultimately, metaperceptions inaugurate a new order of communication: metacommunication. The mutual recognition of perceptions immediately leads to the emergence of communication about communication. The characteristics of metacommunication are thus, closely tied to the degree and features of mutual acknowledgement of perceptions. Metaperceptions and metacommunication are both related systems within interaction. 
At this point, it is most useful to refer the importance of distinguishing levels in communication. This is not the place to discuss how Bateson adapts the Russellian Theory of Logical Types (Bateson, 1972: 279-308; Bateson, 1979: 114) nor how metacommunication involves oxymora and may be related to the paradox of Epimenides: "All Cretans are liars" (being Epimenides a Cretan). To the purposes of this paper, we will follow Bateson's insight that ordinary communication necessarily seldom conforms to these logical rules (cf. Craig, 2016: 2).

We detail two levels associated with communication. "Levels" does not mean a primary and a secondary message, it is above all the distinction between the contents of communication - its communicative code - and the instructions of communications - its communicative directives. Metacommunication is understood by Ruesch \& Bateson (1951: 209) as "communication about communication" encompassing "all the exchanged cues and propositions about (a) codification and the (b) relationships between the communicators". Meaning is, thus, better apprehended, not as a univocal and unique transfer, but mainly as negotiation. It flows from these two levels.

Every instance of communication involves, by one hand, a statement or affirmation of a previous event. And, by the other hand, it comprises a command, be it a cause, or a stimulus for an ensuing event (Ruesch \& Bateson, 1951: 179). This command or instruction is considered to be a second message encompassing the first whose main task is to specify how the message should be apprehended. According to Watzlawick and his colleagues (1967), communication is not just a means to represent and explain reality. It is also a way to express reality. In other words, communication established multiple versions of reality and must be understood as reciprocal comprehension (cf. Porcar \& Hainic, 2011: 14).

Communication is also subject to the other's subjectivity, it is also intercomprehension. Therefore, it must suppose an intrinsic process of orienting the comprehension. As the mechanistic or mathematical notion of message is surpassed by this pragmatic view of communication, the relationship dimension stands along the "content" of communication. And that's why metacommunication is such a fundamental notion to understand the communicational process.

Communication about communication points to this complementary level. Consequently, metacommunication may be considered a second order or second level of communication. However, viewing metacommunication as a second order communication does not suppose metacommunication is a surplus or a parasite to communication. It does not presuppose a hierarchy or a first, primary message, different to a second, marginal, one.

On the contrary, metacommunication seems to be the very nature of the general process of communication. It is communication decomposed in its core. There are not two exclusive processes but metacommunication is the double constitution of communication. Since communication is a process of interaction, metacommunication is its double. This notion should, hence, be taken, not as a replica, but as a second order communication.

Bateson comments that a meta-message is something bringing redundancy to the universe (Bavelas, 1995: 34). But redundancy does not mean that communication is another communication. The expression "communication about communication" indicates, above all, this redundancy-creating relationship. We suggest looking into this redundancy-creating relationship as the matrix or vital movement of communication talking about itself through metacommunication.

One important corollary of it is that it enables us to consider communication beyond a subjective conceptualization such as "intentions". Metacommunication is not always intentional nor fully digital or analogic (Watzlawick et ali., 1967). To the Palo Alto School, communication is a set of actions and rules that make interactions and relationships possible. Intentionality does not determine communication (Porcar and Hainic, 2011: 13). This means 
assessing the "about" in "communication about communication" is not so much a logical problem but a theoretical one to which one could apply a new framework to conceive communication in its particular complexity.

From a practical viewpoint, we could consider "definitions" to be explicit metacommunicative (more specifically, metalinguistic) messages about the semantics of words. But we would like to take this discussion to a more theoretical standpoint and mention how the general process of communication is implicated by metacommunication. It is as if metacommunications were an implicit directive of communication that constitutes, elaborates and transforms it. Metacommunication as a self-reflective torsion of communicative processes. A movement in which, just like a moebius stripe, communication is turned inwards and outwards.

The next section describes the consequences to the object "communication" from the perspective of metacommunication as second order communication.

\section{Consequences of Metacommunication as second order communication: communication ad infinitum}

Communication Theory is not normally concerned with metacommunication but since communication is also redundancy, directive and relationship, we must include in it the interrogation about this communication-other - this metacommunication that is constantly framing and altering communication processes.

Previously, we have approached metacommunication (Mateus, 2015) as a kind of supplement (beyond "something that is added to something else in order to make it complete"- Merriam-Webster Online Dictionary). We want now to enlarge this perspective and examine metacommunication and its significance.

We posit that metacommunication can be understood as a continuous deferral, a second order communication constantly adding up (in an intrinsically way) whose ultimate conclusion points to the recognition of the insurmountable fixation or stabilization of meaning.

This means that metacommunication is permanently overcoming the codified borders of communication. Metacommunication is, thus, meaning remediation, perpetual flux, each message supplementing (cf. Derrida, 1988) communication. Metacommunication and communications are both levels of a process of symbolic sharing and mutual awareness that has no end: communication comes with metacommunication that in this case is also a communication about a communication that is a communication about a communication that is a communication about a communication... The process is one of constantly recommunicating.

This is why we submit the view of metacommunication as re-communicating communication. A redundancy that is not a discourse based on the sameness but a discourse based on the self-difference. In theory, metacommunication does not differentiate from communication. Still, it is a self-differentiating redundancy, an evolving differentiation that paradoxically contains the possibility of communication.

With this regard, metacommunication could be defined as a non-repeatable redundancy, an internal differentiation processes all communication suffers in itself. A selfdifference (cf. Derrida, 1988), inhabiting the very process of communication.

By attending to this self-differentiation, we find the redundancy-relationship of metacommunication an evolving configuration of communication: resonating, dialoguing its multiple filiations and metaperceptions. Having this in mind, the inscription of 
metacommunication, this takes us to consider communication as something moving towards, a perpetual dislocation of meaning.

This underscores an ad infinitum communication, a communication re-communicated and metacommunicated. This is why anything more than communication would not be noncommunication or silence. Anything more than communication would be more communication - its self-disclosure in metacommunication. If all behaviour is potential communication, communication is a process we cannot escape. Even if one tries not to communicate that indication of anti-communication may be in itself metacommunication. It seems we cannot communicate without metacommunicate (Ruesch \& Bateson, 1951) but metacommunication is the other of communication.

As a second order of communication, metacommunication is no discrete or separate entity. In fact, every communication causes metacommunication as a kind of process that is a simple communication about communication but, at the same time, is more than a subsequent communication. It is refracted communication, something we cannot overcome. Something that is behind and beyond communication.

As a second order communication, metacommunication is a re-communicating message rising from within communication. This is why communication is not a process that enclosures us but the really interacting environment where humans live, act and encounter themselves. A possibility always opening itself in metacommunication, a pure potentiality that is never soothed. A communication talking about itself.

At this light, metacommunication is the leaking communication, an extra that is still the own nature of communication. Ad infinitum communication may, thus, be apprehended as the mixing of two central levels of communication where communication becomes metacommunication which becomes more communication which becomes metacommunication. Or, in other words, the consequence to look into metacommunication as a second order communication is the necessity to admit that one does not preceded the other but they form a dialectical, heterogeneous, assorted unity.

One important theory of communication that may shed some light to the concept of metacommunication, as we are describing it, is that of Michel Serres (1969). Communication is to him a notion derived from the idea of declination. Everything is potentially releasing something (energy) in every direction: winds, animals, leafage, everything communicates. He says we are plunged in communication that is structured in relations. We are agents, mere bodies, crossroads, passages. Communication means networks but also multiplicity. The domain of the world is the domain of Hermès, of messengers and communication. Serres is not too far from Watzlawick et ali. (1967) as he also believes that it is impossible to escape communication and to not communicate (Marcondes, 2005: 12). Communication as something made of nodes and intersections and, therefore, permeating all things.

Influenced by Serres, Marcondes Filho (2012) also sees communication as a nomadic activity, in constant displacement and interference. A diffuse but fierce process. His "Nova Teoria da Comunicação" offers a new ontology and epistemology to communication based on non-determination and impermanence. The being of communication is an event-asoccurrence, a causal event marked by friction and impact (Marcondes Filho (2012).

Moreover, what we have in communication are no more than relations. In order to study them Marcondes talks about the methodology of the metaporo: not an absolute method as a fixed route to knowledge but a method made by recompositions, a method that is continuous (re)generation. This point is related to metacommunication since, just like the metaporo, metacommunication discovers paths, give insights and opens new trails in communication. Metacommunication, inspired by the metaporo, is an access to meaning and a glimpse to the other, a micro-event that signals an encounter in interaction. 
Just like the metaporo, metacommunication is like a boat cutting through the waters, opening declinations without a fixed end. It is a spontaneous meeting between two orders of communication.

\section{Conclusion}

In this paper, we dealt with the concept of "metacommunication" from a Communication Theory perspective and searched to theoretically extrapolate some possible effects on the way we consider the "communication" process.

While having in mind an analysis of the meaning of "about" in the definition of metacommunication as communication about communication, we have suggested to consider it as a second order communication.

This means that metacommunication is, not a parasite, an appendix or a repetition, but a self-differentiating redundancy that inhabits the very process of communication. We have described the corollaries of such a view emphasizing the infinite dimension of communication. By considering its contingency and transience, we have briefly mentioned the thought of Michel Serres and Marcondes Filho as useful to deal with the displacement of communication that the idea of metacommunication, as dealt, requires.

We have highlighted that metacommunication pinpoints an infinite communication, in perpetual movement and deferral. Communication and Metacommunication form a dialectical process that form the symbolic environment of man. Metacommunication as the very nature of communication. It is not governed solely by a teleology (telos) and functional means but by spontaneity and relationship in an interaction characterized by reciprocal awareness. Communication is, given its counter-part of metacommunication, dissemination: metacommunication is a kind of second order propagation whose boundaries are open to complete and unprompted redefinition.

In this way, communication and metacommunication are just surfaces where a plurality of intersections, networks and transitions occur. Meaning between two persons is continually circulating between those two levels. And because it crosses the boundaries between individuals, communications must be seen together with metacommunication and the impossibility of not to communicate. By giving full emphasis at this feature, one is simultaneously stressing the relationship aspect of communication: how communication is simply a permanent happening and may not be subject to suspension or even cessation.

But it is also this never-ending communication that metacommunication enables that is key to the possibility of two individuals to orient and coordinate their own behaviours and their behaviours towards each other. If communication was simply a matter of transmission, metacommunication would be simply pure surplusage.

However, since we have suggested a self-differentiating redundancy, we can deal with a metacommunication as a rich and unavoidable part of every communicative act. Communication is something uncertain, a risk but also an asset: it is always a relationship. Its constant redefinition or its smooth gliding only asks for more communication. Metacommunication is the answer to the relationship level of communication. And the only answer daring to challenge the termination of communication. By including this concept on the nomadic and networked conceptions of communication, we gain a renewed perspective on the omnipresence of this process.

We cannot go around communication. And because we continually participate in this ritualistic process, communication is at all times behind and beyond us.

Metacommunication. Metacommunication as self-differentiating communication. 


\section{References}

Andersen, Peter A. (2009). "Metacommunication" In Littlejohn Stephen W \& Foss Karen A. (Ed.), Encyclopedia of Communication Theory. London, Sage.

Baltzersen Rolf K. (2013). "The Importance of Metacommunication in Supervision Processes in Higher Education", International Journal of Higher Education, Vol. 2, No. 2, pp. 128-140. CrossRef

Bateson, Gregory (1972) Steps to an Ecology of Mind. Chicago, The University of Chicago Press. [2000]

Bateson, Gregory (1979). Mind and Nature- a necessary unity. New York, Dutton.

Bavelas, Janet B (1995). "A note on Metacommunication" In Weakland, J., \& Ray, W. Propagations: Thirty years of Influence from the Mental Research Institute, New York: Haworth. 1995, pp. 27-36.

Birdwhistell, Ray L (1959). "Contribution of Linguistic-Kinesic Studies to the Understanding of Schizophrenia" In Auerbach A (ed.), Schizophrenia: an integrated approach, New York: Ronald Press, pp.99-123.

Castor, Theresa R. (2017). "Metacommunication". The International Encyclopedia of Organizational Communication. pp. 1-9.

Centeno, Maria João (2009). O Conceito de Comunicação na obra de Bateson - interacção e regulação, Livros Labcom (Edição digital)

Craig, Robert T (2016), "Metacommunication", The International Encyclopedia of Communication Theory and Philosophy, London, Wiley and Sons.

Dance, Frank (1967)." "A Helical Model of Communication." In Human Communication Theory, edited by Frank Dance. New York: Holt, Rinehart and Winston.

Dewey, John (1927) [1991]. The Public and it's Problems, Swallow Press.

Derrida, Jacques (1988). Limited Inc. Evanston: Northwestern University Press.

Esser, Frank, Reinemann Carsten, Fan David (2001) Spin Doctors in the United States, Great Britain, and Germany - Metacommunication about Media Manipulation. The International Journal of Press/Politics, 6 (1), 16-45. CrossRef

Grice, Paul (1975). "Logic and conversation". In Cole, P.; Morgan, J. Syntax and semantics. 3: Speech acts. New York: Academic Press. pp. 41-58

Jensen, Klaus Bruhn (2016). "Been There, Done That. Communication, MetaCommunication and Presence", Nordicom Review, 37(special issue): 7-22. CrossRef

Marcondes Filho, Ciro. (2005). "Michel Serres e os Cinco Sentidos da Comunicação". Novos Olhares, São Paulo, p. 5-19

Marcondes Filho, Ciro (2012). O princípio da razão durante - O conceito de comunicação e a epistemologia metapórica - Nova Teoria da Comunicação III - Tomo V. São Paulo: Paulus.

Mateus, Samuel (2015). "There is no outside of communication -Metacommunication at the light of Derrida's graphematic structure of communication" In Marcos, ML, Babo, MA, Santos R. (org.), Jacques Derrida. CECL/Unileya.

Nakano, Shigeru (2001). "The Basic Structure of Metacommunication in Intersubjective FunInteractions between mothers and infants: analysis of two contrasting cases". Research and Clinical Center for Child Development Annual Report, 23: pp. 39-49

Porcar, Codruta, Hainic, Cristian (2011). "The Interactive Dimension of Communication: the pragmatics of the Palo Alto Group, Journal for Communication and Culture, 1, no. 2: 4-19

Rogers, L. E., \& Escudero, V. (2004). Relational communication: An interactional perspective to the study of process and form. Mahwah, NJ: Erlbaum 
Rich, M.H., \& Craig, R.T. (2012). Habermas and Bateson in a world gone MAD: Metacommunication, paradox, and the inverted speech situation. Communication Theory, 22(4),383-402. CrossRef

Ruesch J, Bateson G (1951). Communication - the social matrix of psychiatry, New York: WW Norton \& Company

Serres, Michel (1969). Hermès I, la communication, Paris : Éditions de Minuit.

Sfez, Lucien (1992). Critique de la communication. Paris : Éditions du Seuil.

Shannon, Claude E. and W. Weaver (1949) [1964]. Mathematical Theory of Communication. Urbana: University of Illinois Press.

Simons, H. W. (1994). "Going meta": Definition and political application. Quarterly Journal of Speech, 80, 468-481 CrossRef

Watzlawick P, Beavin J, Jackson D (1967) [2011]. Pragmatics of Human Communication - a study of interactional patterns, pathologies and paradoxes, New York, London: WW Norton \& Company. 